\title{
CRISE E REFORMA DA ORGANIZAÇÃO MUNDIAL DA SAÚDE
}

\author{
Deisy Ventura e \\ Fernanda Aguilar Perez
}

Crise e reforma são palavras que acompanham a trajetória das organizações internacionais (OIs), fadadas a conciliar os imperativos da realização de suas funções com a heterogênea vontade dos seus Estados-membros. O objetivo deste artigo é mostrar que a Organização Mundial da Saúde (OMS) constitui um dos mais ricos exemplos das tensões que permeiam as OIs na atualidade e, por conseguinte, que o processo de reforma da Organização, atualmente em curso, merece maior atenção da comunidade acadêmica brasileira.

Originalmente considerada a "autoridade moral e porta-voz da saúde no mundo" (OMS, 2011a, p. 11), diretora e coordenadora da atuação internacional no domínio da saúde (OMS, 1946), a OMS oferece uma espécie de "enquadramento político e técnico" aos Estados em matéria de saúde pública (OMS, 2011a, p. 12). Contudo, nas palavras de sua atual diretora-geral, Margaret Chan, "a OMS está sobrecarregada e é incapaz de responder com agilidade aos desafios da saúde global" (Sridhar e Gostin, 2011, p. 1585). Depois de ver reduzido o seu protagonismo diante da concorrência com outros organismos internacionais e entidades privadas, inclusive as filantrópicas, cresceram as 
dificuldades de financiamento e também o dissenso acerca de quais devem ser as suas prioridades de atuação. Recentemente, a pandemia de gripe A (H1N1), ocorrida entre 2009 e 2010, deu à crise da OMS uma inédita dimensão. Denúncias de conflito de interesses dos especialistas da OMS, ou até mesmo de que nunca houve uma verdadeira pandemia, encontraram eco no meio científico, na mídia da maior parte dos países e até em comissões parlamentares de inquérito (Ventura, 2013a). Para alguns, "a OMS enganou o mundo inteiro" (Gentilini apud Bussard, 2012). Para outros, a OMS estaria simplesmente "fora de moda, subfinanciada e superpolitizada" (Chow, 2010).

Após breve apresentação da OMS, este artigo buscará identificar os principais elementos de sua crise, graças à revisão da literatura especializada e da consulta aos documentos da própria Organização, complementada por pesquisas em arquivos de jornais e revistas. Num segundo momento, serão resumidos os resultados de nossa pesquisa empírica sobre a 46 presença de pautas de reforma na ordem do dia da Assembleia Mundial da Saúde, principal órgão decisório da OMS, de 1998 a 2014, período em que se constatará a recorrência do binômio crise e reforma. Faremos, a seguir, breve alusão às posições do Brasil e da União Sul-Americana de Nações (Unasul) a respeito do processo de reforma da Organização, que revela, em nossa opinião, uma promissora faceta da integração regional. Por fim, questionamos se a reforma em curso tornará a OMS um "enclave cosmopolítico" (Held, 2007, p. 434) na complexa configuração da saúde global.

\section{A OMS como "lugar único na saúde global"}

Herdeira de um século de cooperação sanitária ${ }^{1}$, a OMS foi criada em 1946, pela Conferência Internacional de Saúde

\footnotetext{
${ }^{1}$ Em 1851, vinte anos após a irrupção do cólera na Europa, Paris sediou a primeira Conferência Sanitária Internacional, com o objetivo de chegar a um acordo, entre doze Estados, sobre as prescrições mínimas da quarentena marítima, a fim de "prestar importantes serviços ao comércio e à navegação" (OMS, 1958, p. 6) .
} 
de Nova York, e é atualmente composta por 194 Estados-membros (OMS, 2014c). Membro do sistema da Organização das Nações Unidas (ONU), ela é uma das organizações mais descentralizadas da família (Godlee, 1994). Aos seus seis escritórios regionais - África, Américas, Ásia do Sudeste, Europa, Mediterrâneo Oriental e Pacífico Ocidental incumbe, em síntese, formular diretrizes para a respectiva região, bem como executar as decisões da sede, localizada em Genebra (Suíça), de cuja elaboração elas também participam. A OMS mantém, ainda, 150 escritórios em países, zonas ou territórios, nos quais trabalham mais de 7 mil pessoas de mais de 150 nacionalidades (OMS, 2014c).

Para além de sua vasta abrangência geográfica, a OMS ocupa um "lugar único na saúde global, graças à sua visionária carta constitutiva - denominada Constituição, o que é incomum no sistema onusiano - que assegura um enfoque social da saúde, e afirma a saúde como um direito humano" (Legge, 2012). Assim, a OMS muitas vezes recorreu ao discurso dos direitos humanos para enfrentar as restrições habituais da diplomacia dos Estados (Biehl e Petryna, 2013, p. 3).

Seguindo a tradição onusiana, a OMS é governada por um triângulo institucional básico, constituído pela Assembleia Mundial da Saúde (AMS), pelo Conselho Executivo (CE) e pela Direção-Geral (DG).

A AMS é o grande plenário, reunido anualmente em Genebra, em que cada Estado-membro tem direito a um voto. Cabe à AMS fixar a política geral da Organização, adotar decisões e recomendações, editar normas, votar o orçamento e criar as comissões necessárias à realização de suas

Nos primeiros cem anos da chamada diplomacia sanitária internacional, um "imenso corpo de direito internacional sobre saúde pública, hoje largamente esquecido, foi criado", cujas características básicas são: a tendência de internacionalizar a saúde em função do comércio; a necessidade de cooperação que os riscos de contaminação impunham aos Estados; o envolvimento de corporações multinacionais e de atores não governamentais em numerosas iniciativas; e a grande diversidade entre os resultados dos diferentes regimes jurídicos adotados (Fidler, 2001, p. 846). 
funções. Seu sistema de votação por maioria, a depender do caso, qualificada ou simples, estende-se ao CE e às comissões.

Ao CE compete aplicar as decisões da AMS, preparar suas sessões e endereçar-lhe proposições; deve, ainda, apresentar-lhe, para exame e aprovação, seus programas gerais de trabalho ${ }^{2}$. Cabe também ao CE tomar medidas de urgência para tratar de acontecimentos que exijam ação imediata.

Quanto à DG, é nomeada pela AMS, sob proposta do CE, a quem está sujeita ${ }^{3}$. Para garantir a independência da DG e do pessoal da OMS, a Constituição os proíbe de solicitar ou receber instruções de governos ou autoridades estranhas à Organização.

As funções da OMS encontram-se no cerne do debate sobre a reforma; eis que ela superou uma origem marcadamente higienista para chegar a uma grande ampliação de seus domínios de atuação. Segundo o plano de trabalho em vigor até 2015, as funções básicas seriam atualmente: exer48 cer a liderança em temas cruciais para a saúde, e participar de alianças quando ações conjuntas são necessárias; determinar linhas de pesquisa e estimular a produção, difusão e aplicação de conhecimentos; editar normas, promover e acompanhar de perto sua aplicação prática; formular opções de políticas de saúde em conformidade aos princípios éticos e fundamentos científicos; prestar apoio técnico, catalisar as mudanças e gerar capacidade institucional duradoura;

\footnotetext{
2 O Conselho Executivo é composto por 34 Estados-membros, eleitos pela AMS com mandato de três anos, buscando uma distribuição equitativa por região. Atualmente, são eles: África do Sul, Eritreia, Gâmbia, Libéria, Namíbia, República Democrática do Congo e Tchad (África); Argentina, Brasil, Cuba, Estados Unidos, Panamá e Suriname (Américas); Maldivas, Nepal e Coreia do Norte (Ásia do Sudeste); Albânia, Andorra, Azerbaijão, Bélgica, Croácia, Lituânia, Reino Unido e Rússia (Europa); Arábia Saudita, Egito, Kwait, Irã e Líbano (Mediterrâneo Oriental); Austrália, China, Coreia do Sul, Japão e Malásia (Pacífico Ocidental) (OMS, 2014c).

${ }^{3}$ O sanitarista carioca Marcolino Gomes Candau dirigiu a Organização durante duas décadas: de 1953 a 1973. Foi a época da construção da sede, em Genebra, e igualmente de uma das atualizações do Regulamento Sanitário Internacional, além do lançamento do bem-sucedido programa de erradicação da varíola (Lima, 2002; Kaplan, 1983; BMJ, 1973).
} 
seguir de perto a situação em matéria de saúde e determinar as tendências sanitárias (OMS, 2006).

Num grande esforço de síntese, podemos dividi-las em três categorias de funções (Laude, Mathieu e Tabuteau, 2007). A primeira corresponde à tradição histórica das instituições sanitárias, de luta contra as grandes patologias e de organização da vigilância epidemiológica, tendo como principal instrumento o Regulamento Sanitário Internacional (RSI), que estipula direitos e obrigações dos Estados relativos à organização sanitária, regulamentação de transportes internacionais e medidas para evitar a propagação de enfermidades. Segundo a Constituição da OMS, os regulamentos dispensam procedimentos de incorporação às ordens jurídicas nacionais, valendo-se da técnica do opting out ${ }^{4}$.

A segunda categoria de missões da OMS diz respeito à elaboração de normas sanitárias internacionais. Segundo a sua Constituição, a OMS pode adotar acordos ou convenções, que entram em vigor para os Estados-membros quando de sua incorporação às ordens nacionais pelos respectivos processos constitucionais. Ademais, a OMS mantém intensa produção normativa do que se costuma chamar de soft law, ou seja, de regras de natureza recomendatória, produzindo uma pletora de padrões técnicos, guias e

\footnotetext{
${ }^{4}$ Enquanto o opting in corresponde ao ato positivo pelo qual um Estado decide sujeitar-se a um ato ou instrumento convencional, típico do direito dos tratados (representado por expressões como assinatura, aprovação, ratificação ou adesão), o opting out aparece normalmente nos processos decisórios relativos à adoção de normas técnicas pelas organizações internacionais, em que normalmente se vota por maioria simples ou qualificada, nos quais o Estado pode expressar sua intenção de não aplicar certa norma técnica, valendo-se do opting out total (expresso em vocábulos como recusa ou não aprovação) ou parcial (traduzido por termos como objeção e reserva). Assim, a ratio legis da técnica de opting out é guiada pela preocupação em encontrar um equilíbrio entre a autonomia da vontade dos Estados e o exercício das competências normativas das organizações internacionais (Mbengue, 2006, p. 201). O RSI (de 2005) foi objeto de apenas duas reservas, da Índia e dos Estados Unidos, sendo a última, especialmente no que atine às questões federativas, objetada pelo Irã; China, Grécia, Portugal, Turquia e Tonga formularam declarações interpretativas do Regulamento (OMS, 2008).
} 
boas práticas (Burci, 2012). A repercussão dessas normas é imensurável, tanto quanto a pressão do setor privado para influenciá-las, como revelam os exemplos do Codex Alimentarius $^{5}$ e da Lista modelo de medicamentos essenciais ${ }^{6}$.

O terceiro e último ramo funcional da OMS seria o das intervenções sanitárias. Ela define e implementa diretamente diversos programas de luta contra as grandes doenças (como tuberculose, malária etc.), além de apoiar a pesquisa sobre doenças transmissíveis (gripe, aids etc.) ou não transmissíveis (câncer, doenças cardiovasculares etc.). Oferece, igualmente, assistência técnica aos países menos avançados (vacinação contra doenças infecciosas, provisão de água potável etc.). No mesmo diapasão, a OMS elabora importantes relatórios sobre problemas de saúde pública, com o escopo de produzir e difundir informações, e propor estratégias aos Estados-membros e atores sociais. Eles influenciam a composição da imagem que "o mundo faz de si mes50 mo” em matéria de saúde (Ventura, 2013a, p. 94). Exemplo disso é o impacto de alguns desses relatórios: há um antes e um depois em matéria de avaliação da performance dos sistemas de saúde, graças ao relatório mundial sobre o tema, elaborado pela OMS em 2000; o mesmo se pode dizer do

${ }^{5}$ Elaborado pela Comissão do Codex Alimentarius, aprovada na Conferência da Organização da Alimentação e Agricultura (FAO), de 1961, e na AMS de 1963, com a função de constituir e executar o Programa Conjunto FAO/OMS sobre Normas Alimentares. Vê-se que a Comissão trata "os produtos principalmente como commodities e não como alimentos em sua dimensão total e em sua importância vital para os seres humanos. Seu processo segue as diretrizes e a lógica do sistema industrial de produção, que direciona hoje toda a produção agropecuária, e a ele responde mais do que à preocupação com os graves problemas do acesso da população à comida (food security) e à segurança sanitária (food safety)" (Lucchese, 2003, p. 553).

${ }^{6}$ Esta lista de medicamentos é elaborada no âmbito de um programa da OMS, com o apoio de um grupo de especialistas, a fim de identificar o mínimo que deve ser disponibilizado à população em qualquer país. Embora se trate de uma extraordinária forma de pressão sobre os governos dos países em desenvolvimento, o que explica a forte presença do setor industrial no debate que cerca a escolha dos medicamentos, essa lista não é discutida na AMS e suas modificações são ainda menos transparentes que o conjunto do trabalho da OMS (Charpak, 2013, p. 13). 
impacto do relatório mundial sobre os fatores de risco para a saúde, divulgado em 2002, indicando o papel do tabaco, do álcool, de certos alimentos e do sedentarismo no desenvolvimento de doenças (Danzon e Charpak, 2012).

\section{Os novos atores da saúde global e a crise da OMS}

A expressão crise já aparece na literatura sobre a OMS dos anos 1990 (Tollison e Wagner, 1993; Godlee, 1994; Deveaud e Lemennicier, 1997). Entre as numerosas dificuldades enfrentadas pela OMS na realização das funções, identificamos, tanto na literatura como nos documentos oficiais, os cinco principais elementos da crise na organização. São eles: a erosão do seu protagonismo; a escassez e a natureza do seu financiamento; os conflitos de interesse dos especialistas, que vieram à tona durante a gestão da pandemia de gripe $\mathrm{A}(\mathrm{H} 1 \mathrm{~N} 1)$; as dificuldades de comunicação; e os problemas de governança interna. Nesta parte do artigo, abordaremos os dois primeiros elementos.

No que se refere à crise de liderança, o paradigma predominante da saúde internacional, desde a sua criação, foi o predomínio da ação dos Estados sob a coordenação da OMS (Biehl e Petryna, 2013). Nas primeiras décadas de funcionamento da Organização, os ministros da saúde eram, de fato, as maiores autoridades mundiais na matéria (Chow, 2010). Ocorreram naquele período vitórias importantes como a erradicação da varíola, em 1979, resultante da grande campanha da OMS que aumentou o financiamento para produção de imunizantes em laboratórios localizados nos países endêmicos, garantiu maior fiscalização da qualidade dos produtos, além de introduzir a vacina liofilizada e a agulha bifurcada em larga escala (Muniz, 2011). O sucesso desse programa influenciou os sistemas nacionais de saúde, ao disseminar o otimismo quanto à possibilidade de erradicação de doenças e deixar clara a necessidade de fortalecer os serviços básicos de saúde (Muniz, 2011, p. 700). 
Não obstante, as aspirações da OMS são historicamente condicionadas pela multiplicidade de pontos de vista, necessidades e preferências dos seus Estados-membros (OMS, 2011a). Exemplo disso é a crítica de que haveria uma "politização" da OMS, formulada pelos países industrializados, especialmente os Estados Unidos, para quem essa OI deve ser um órgão técnico cujas atividades devem ser baseadas exclusivamente em evidências biomédicas. Quando a OMS lançou a campanha Saúde para todos no ano 2000, com ênfase na saúde primária, interpretou-se que ela estava respondendo à pressão de países em desenvolvimento, que agora conformavam maioria na AMS (Brown, Cueto e Fee, 2006; McInnes e Lee, 2012, p. 127).

Ronald Reagan, presidente dos Estados Unidos entre 1981-1989, pressionado pelo Congresso, deixou claro à época o descontentamento do país com "a predominância de países do Terceiro Mundo em agências da ONU” (Chorev, 52 2012, p. 125). Instituições norte-americanas, como a Fundação Rockefeller e a Fundação Heritage, opunham-se à ideia do projeto Saúde para todos (Nuruzzaman, 2007; Birn, 2009). A Fundação Heritage chegou a lançar um estudo intitulado A OMS: resistindo às pressões ideológicas do Terceiro Mundo, enfatizando que a OI deveria ser somente um órgão técnico (Birn, 2009).

Por conseguinte, visando ao controle da instituição (McInnes e Lee, 2012) e com o apoio de outros países industrializados (Chorev, 2012), os Estados Unidos aplicaram a política de zero crescimento real do orçamento da OMS para os anos de 1980 e de zero crescimento nominal nos anos 1990. Assim, ao tentar adaptar-se à lógica neoliberal (Chorev, 2012), a instituição teria perdido seu papel de guia nas políticas de saúde, tanto por seus próprios defeitos como pelo desinteresse dos Estados (Berlinguer, 1999).

Paralelamente, a partir do final dos anos 1980, uma guinada no conceito de desenvolvimento do Banco Mun- 
dial fez com que ele expandisse sua atuação em matéria de População, Nutrição e Saúde (em inglês, PNH), tornando-se hoje o maior financiador externo da saúde e um dos maiores apoiadores na luta contra o HIV/aids (Ruger, 2005). Na primeira década do século XXI, a saúde ascende à agenda de instâncias como o Conselho de Segurança e a Assembleia Geral da ONU; torna-se tema das "great power conferences, e chega às cúpulas dos G7/8/20/77” (Kickbusch e Ivanova, 2013, p. 22). Daí resultam parcerias mundiais com o setor privado industrial e os mecenas filantrópicos, cujos pesos político e financeiro acarretam a imposição de suas próprias prioridades, ameaçando a autoridade e a independência da OMS (Kerouedan, 2013).

Logo, houve uma mudança radical nas últimas décadas: as empresas transnacionais e os imperativos de mercado passaram a desempenhar um papel importante, por vezes perverso, na formulação de políticas de saúde (Maruthappu e Williams, 2012). No atual contexto de saúde global, doadores privados e organizações, governamentais ou não, com as mais variadas agendas, parecem alcançar o mesmo peso que os organismos multilaterais, e a OMS tem se mostrado "disposta a renunciar a uma parte de sua liderança nas iniciativas de saúde pública, tanto no plano nacional como no global" (Cueto, 2013, p. 51).

A questão do financiamento da OMS é um dos aspectos cruciais dessa crise. Embora a atuação da organização tenha se ampliado nos últimos anos, há evidente decréscimo das contribuições dos Estados para a Organização, as quais, atualmente, constituem apenas cerca de $20 \%$ das receitas fixas, quando representavam, em 1998-1999, cerca de 50\% delas (OMS, 2011b, p. 2).

As contribuições voluntárias, que complementam as receitas fixas, são em grande parte destinadas a programas específicos, aos quais são formalmente vinculadas. Trata-se da chamada doação earmarked, realizada "em dinheiro, 
'carimbada' para determinada finalidade ou projeto, ao gosto do doador, só podendo ser gasta naquela específica destinação", o que tende a "distorcer as prioridades programáticas definidas pelos Estados-membros", além de dar margem a "conflitos de interesses que possam advir, por exemplo, de doações da indústria farmacêutica e outras entidades privadas" (Buss et al., 2012, p. 1484). Logo, é provável que a ampliação das atividades da OMS esteja mais relacionada ao desejo dos doadores do que à crença de que ela é o ator mais adequado para cumprir as novas tarefas.

Assim, as contribuições voluntárias provêm de alguns Estados-membros que desejam financiar iniciativas precisas, mas também de fundações filantrópicas e do setor privado (inclusive de laboratórios farmacêuticos). No biênio 2010-2011, por exemplo, a Fundação Bill \& Melinda Gates foi a maior doadora voluntária de fundos à OMS (US\$ 446.161.801,00), sobrepujando até mesmo as contribuições voluntárias dos 54 Estados Unidos, de US\$ 438.285.683,00 (OMS, 2012a, p. 10). A Fundação Gates fez uso da palavra na abertura de três AMSs - em 2005, 2011 e 2014 (OMS, 2014f). Em seu discurso de 2014, Melinda Gates afirmou: "salvar recém-nascidos é um ato bondoso de amor que também tem significado empresarial e pragmático" (OMS, 2014f, p. 5).

Para o biênio 2012-2013, a OMS teve um orçamento total de US\$4,210 bilhões em fundos disponíveis, dos quais US $\$ 2,524$ bilhões foram destinados aos programas de base, US \$1,302 bilhão para programas especiais e dispositivos de colaboração, e US\$ 384 milhões para intervenções em caso de epidemias e crise; US\$ 916 milhões são provenientes de contribuições fixas dos Estados-membros, enquanto US\$ 3,294 milhões provêm de contribuições voluntárias (OMS, 2014b, p. 39). Na distribuição interna dos recursos, aparece a sede genebrina como a principal destinatária, consumindo 31,06\% dos fundos disponíveis; a seguir, surge a região africana, gastando 29,19\% (OMS, 2014b, p. 44). 
Num rápido esforço comparativo, note-se que, apenas no exercício financeiro de 2013, o Banco Mundial investiu diretamente mais de US\$2,4 bilhões em PNH, além de gerenciar um portfólio total de US\$ 8,7 bilhões em 65 países (Banco Mundial, 2013, p. 13).

A variação dos atores e a nítida emergência da saúde global como tema das relações internacionais (Kickbusch e Ivanova, 2013, p. 22) não significou, porém, um progresso: "a governança mundial da saúde é lamentavelmente deficiente" (Gostin, 2007, p. 226) e "o mundo está mal preparado para enfrentar qualquer emergência de saúde pública mundial prolongada e que constitua uma ameaça" (OMS, 2011a, p. 13). Os inquietantes indicadores de saúde da larga maioria da população mundial ${ }^{7}$ revelam que "nós não damos o mesmo valor a todos os seres humanos" (Kerouedan, 2013, p. 74).

Por outro lado, mas ainda em matéria de protagonismo, "a OMS possui, graças à sua Constituição, vastos poderes, mas seu potencial nunca se realizou” (Gostin, 2007, p. 226). Em quase sete décadas, a OMS só editou um regulamento importante (o RSI, cuja versão atualmente em vigor é a de 2005) e um tratado, qual seja, a Convenção-quadro para a Luta Antitabaco, de 2003 (Sridhar e Gostin, 2011, p. 1586). No campo jurídico, parece predominar a crítica de que a OMS “distanciou-se de sua competência de fazer o

\footnotetext{
${ }^{7}$ Entre incontáveis exemplos das profundas desigualdades que se refletem na saúde pública, limitamo-nos a citar apenas três, que nos parecem bastante significativos. A esquistossomose ainda é uma das doenças de maior prevalência no mundo; em 2011, das 247 milhões de pessoas infectadas, apenas cerca de 10\% teriam recebido tratamento (OMS, 2013b). Já a mortalidade materna em países em desenvolvimento é quatorze vezes maior do que em países desenvolvidos (OMS, Unicef, Banco Mundial; United Nations Population Division, 2014). Por fim, no que atine ao saneamento básico, em relatório conjunto com a Unicef, a OMS revelou que, em 2012, 783 milhões de pessoas não tinham acesso à água potável (cerca de 11\% da população mundial); que 2,5 bilhões de pessoas não possuem instalações sanitárias adequadas, numa redução de apenas $7 \%$ em relação aos dados de 1990; e que cerca de 1 bilhão de pessoas defecam a céu aberto, isto é, cerca de $15 \%$ da população mundial (OMS e Unicef, 2014).
} 
direito porque ela se apresentou principalmente como uma agência científica e técnica" (Gostin, 2007, p. 226).

Gostaríamos de trazer duas ponderações a esta crítica. A primeira é a extraordinária importância do RSI e da convenção antitabaco, cuja repercussão ainda merece estudos empíricos aprofundados, mas jamais foi negada, nem pela literatura, nem pelos Estados. Nos últimos dez anos, a notável evolução das normas nacionais sobre o controle do tabaco são, em grande parte, transposições diretas ou adaptações da convenção da OMS (Danzon e Charpak, 2012). Em segundo lugar, como agência científica e técnica, a OMS produziu uma normatividade cujo problema não é a ineficiência nem a escassez, mas a opacidade das condições de sua elaboração e dos interesses que contempla. É provável que o intenso recurso à soft law seja menos uma limitação da OMS e mais um desejo dos atores mais influentes na produção dessa normatividade.

\section{A pandemia de gripe A (H1N1): crise sanitária, crise política}

Já nos anos 1990, o British Medical Journal publicava: “a OMS tem um problema de imagem. As pessoas sabem que ela existe e muita gente sabe que ela erradicou a varíola, mas poucos têm uma ideia clara do que ela faz", e em geral são membros de associações médica ou profissionais que lidam com padrões técnicos internacionais (Godlee, 1994, p. 1424).

Embora tenhamos mostrado que a crise da OMS começa muito antes, acreditamos que a pandemia de gripe A (H1N1) de 2009-2010 representa, ao longo de sua história, a maior exposição pública das disfunções da Organização. Tivemos, naquela época, a experiência tangível de que "a crise sanitária é uma crise epidemiológica, médica e também, indissociavelmente, uma crise política e uma crise de governo" (Zylberman, 2012, p. 40). O caso da pandemia é 
complexo e mereceu um longo e específico estudo, feito por Ventura (2013a). No âmbito deste artigo, cabe destacar apenas alguns de seus aspectos, que atingiram a credibilidade da Organização.

Em abril de 2009, a DG da OMS declarou que a epidemia de gripe A (H1N1), surgida no México com a denominação de gripe suína, era uma Emergência de Saúde Pública de Importância Internacional (ESPII). Foi a primeira vez que a nova versão do já citado RSI, adotado em 2005, foi utilizada. Ela aporta uma mudança importante: em lugar de prever o combate a doenças específicas, como as versões anteriores, ele cria essa nova categoria da ESPII, focada na definição de "ameaça". Note-se que a conversão dos temas de saúde pública em temas de segurança tem sido presença constante na literatura (Nunes, 2014, p. 5). Grosso modo, o destravamento das longas negociações da nova versão do RSI foi motivado, entre outras razões, por dois grandes eventos: os atentados de 11 de setembro de 2001, em Nova York, e outros ataques que a eles se seguiram, com o uso de antraz, e a Síndrome Respiratória Aguda Grave (SARS), ocorrida entre os anos de 2002 e 2003, que deu ao mundo uma ideia de quais seriam as dimensões de uma pandemia na era da globalização (Ventura, 2013a, pp. 15254). Na perspectiva da Organização, "o fato de considerar doenças infecciosas como ameaças para a segurança mundial e nacional oferece a possibilidade de obter uma direção política de alto nível para apoiar a planificação intersetorial necessária” (OMS, 2005, p. 4). Em outras palavras, os ministérios da saúde passariam a ter, nessas crises, maior peso interministerial. Por outro lado, não se pode deixar de questionar os efeitos da submissão da saúde pública à lógica da segurança internacional.

Em junho de 2009, a DG da OMS elevou ao nível máximo o alerta da pandemia de influenza A (H1N1). Do mesmo modo que na declaração da ESPII, ela se baseou na opinião 
de um Comitê de Emergências, composto por especialistas escolhidos pela própria DG. Os Estados-membros da OMS estão excluídos desse processo de tomada de decisão, exceto o(s) Estado(s) onde tem início a ameaça. Essas declarações podem vir a ter pesadas consequências sobre os direitos humanos (restrição de liberdades, em especial de circulação de pessoas e de reunião; em alguns países, medidas de isolamento, tratamento obrigatório etc.) e sobre a economia (decréscimo do turismo, restrição da circulação de bens etc.). Apesar do peso decisivo dos especialistas na declaração da pandemia, seus nomes só foram publicados quando seu trabalho foi encerrado, sob o pretexto de "proteger os peritos de influências comerciais ou outras. Eles mesmos felicitaram essa decisão, considerada uma medida de proteção e não uma tentativa de tornar secretas suas deliberações e suas decisões" (OMS, 2010c, p. 1).

Até 15 de agosto de 2010, 18.631 óbitos foram noti58 ficados à OMS, embora estudos recentes estimem que a dimensão da pandemia foi dez vezes maior (Simonsen et al., 2013). No entanto, mesmo nas piores estimativas, a pandemia teria causado um número de mortes inferior ao das gripes sazonais - segundo a OMS, de 250 mil a 500 mil casos. Em 10 de agosto, a DG já havia anunciado o final da pandemia (OMS, 2010a).

Durante a pandemia, a independência dos especialistas e da própria OMS foi questionada. Publicações de grande impacto, como a revista norte-americana Science, difundiram acusações de que especialistas vinculados à OMS teriam "incitado ao temor à pandemia para promover seus próprios interesses comerciais no desenvolvimento de vacinas" (Enserink, 2009, p. 350). A OMS reconheceu a legitimidade dos questionamentos: "em razão das divergências entre aquilo que se esperava e o que se produziu na realidade, pode-se compreender essa busca de motivos secretos ou de intenções dissimuladas que a OMS ou seus conselheiros 
científicos poderiam ter, mas ela não é justificada" (OMS, 2009, p. 1).

Em janeiro de 2010, o CE convocou um Comitê de Revisão sobre o funcionamento do RSI (2005) em relação à pandemia de gripe A (H1N1) em 2009, que foi apresentado como um mecanismo independente (OMS, 2010c) dotado de dois objetivos: efetuar o primeiro exame periódico do RSI e "o estudo da resposta que a OMS ofereceu a esta pandemia. Esses dois objetivos são diferentes, mas estreitamente vinculados" (Fineberg, 2011). No dia seguinte à convocação do CE, foi emitida uma declaração da OMS sustentando que: "as políticas e intervenções adotadas pela OMS diante da pandemia de gripe não foram indevidamente influenciadas pela indústria farmacêutica (OMS, 2010b, p. 1).

Numa espécie de comédia de erros, a OMS chegou a nomear para o Comitê de Revisão dois membros do próprio Comitê de Emergências que havia declarado a ESPII (Emergência de Saúde de Importância Internacional), e supostamente teria seu trabalho avaliado pelo "mecanismo independente" (Ventura, 2013a, p. 215). Entrementes, uma investigação promovida pelo British Medical Journal conjuntamente com The Bureau of Investigative Journalism, revelou o envolvimento de consultores da OMS com a indústria farmacêutica (Cohen e Carter, 2010). Denunciou, ainda, diversos consultores da OMS que teriam sido recompensados financeiramente pela indústria por sua apologia à eficácia dos antivirais - como o Tamiflu, da Roche, ou o Relenza, da GlaxoSmithKline - ou pela defesa da necessidade de compra de vacinas, sem que declarações de interesse ou outras informações a respeito de seus vínculos com a indústria farmacêutica fossem mencionados pela OMS em sua gestão da crise.

Editorial do British Medical Journal criticou o "comitê de emergência secreto", cuja decisão deflagrou contratos milionários de compras de vacinas em todo o mundo (Godlee, 2010). Margaret Chan respondeu: "em momento algum, 
nem por um segundo, os interesses comerciais interferiram em minha tomada de decisão", acrescentando: "as acusações de que a OMS teria mudado sua definição de pandemia para que compreendesse um evento menos grave, e então servir aos interesses da indústria, não correspondem aos fatos" (OMS, 2010c).

Na esteira dessas denúncias, a Assembleia Parlamentar do Conselho da Europa (APCE), composta por 47 Estados, adotou uma Resolução (APCE, 2010b) e uma Recomendação (APCE, 2010a), dizendo-se alarmada pelo modo como a pandemia fora gerida, não somente pela OMS, como também pelas autoridades competentes no âmbito da União Europeia. Nesses documentos, a APCE deplorou as reticências da OMS em compartilhar certas informações essenciais, tais como os nomes e as declarações de interesse dos membros do Comitê de Emergências, e também que a OMS não tenha reagido rapidamente, reavaliando sua posição 60 quando se constatou que a gravidade da pandemia não era a prevista. Por fim, indicou a necessidade de que, em um processo de declaração de pandemia, "um vasto leque de perícias e de pareceres seja levado em conta, inclusive pareceres contrários de peritos particulares e de organizações não governamentais" (APCE, 2010b, 6.3.1).

Alguns Estados europeus promoveram comissões parlamentares de inquérito, como foi o caso do Senado francês, onde uma CPI foi criada sobre o papel da indústria farmacêutica na gestão governamental da gripe A (H1N1), sob a justificativa de que "esta gestão calamitosa marca a falência de um sistema que repousa essencialmente sobre especialistas recrutados menos por suas competências do que pelos vínculos que mantêm com a indústria farmacêutica" (França, 2010a, p. 4). Segundo o Senado francês, uma gigantesca manipulação teria transformado uma epidemia de gripe banal numa pandemia de nível 6 , em grande benefício da indústria farmacêutica (França, 2010b). 
É curioso que, apesar da gravidade das acusações, Margaret Chan foi reeleita para a DG da OMS em 2002, como candidata única, sem que qualquer objeção, inclusive parlamentar, fosse formulada pelos Estados-membros (Charpak, 2012).

Segundo o Comitê de Revisão, porém, "em numerosos aspectos, a OMS saiu-se bem de sua tarefa durante a pandemia", malgrado "as dificuldades sistêmicas" e "algumas carências"; finalmente, "o Comitê não constatou nenhuma violação das regras” (OMS, 2011a, p. 13). Não obstante, a DG relatou ter, sob recomendação do Comitê, aumentado o número de campos de especialidade de suas listas de perito, passando de 53 áreas, em 2009, a 76 em 2012; teria, ademais, em cerca de um ano, incorporado 200 novos peritos às suas listas (OMS, 2012d, p. 6).

O resultado disso é que, segundo a própria associação dos funcionários da Organização, "a imagem da OMS na mídia é ruim, o que não contribui nem para atrair fundos nem para melhorar o moral de seu pessoal" (OMS, 2012c, p. 6). A OMS tem investido no reforço de sua presença no espaço público, especialmente nas redes sociais. Segundo dados oficiais, a página da OMS no Facebook passou de 40,5 mil "fãs" em 2012 a 675 mil em 2014; já no Twitter, a conta @WHO teria passado de 311 mil "seguidores" em 2012 a 1,21 milhão em 2014, sendo considerada uma das cinco OIs com melhor performance nesta rede, entre as 101 OIs que foram examinadas pelo The Twiplomacy Study 2013 (OMS, 2014a).

\section{Três décadas de reforma}

No que tange à reforma da OMS, os esforços de visibilidade na mídia e nas redes sociais parecem inócuos, eis que os documentos disponíveis são "verdadeiros florões da linguagem tecnocrática” e, mesmo para iniciados, parecem "numerosos, volumosos, repetitivos e pouco inteligíveis" (Ventura, 2013a, p. 123). 
Na literatura, a OMS chega a ser referida como uma "burocracia pedante", acometida por problemas como "falta de agilidade institucional", "nepotismo político" e "falta de autoridade" (McInnes e Lee, 2012, p. 122). Tais problemas institucionais teriam ficado evidentes durante os dois mandatos de Hiroshi Nakajima, que foi diretor-geral da organização entre 1988 e 1998 (Abbasi, 1999).

Em 1992, o Conselho Executivo criou um grupo de trabalho para delinear uma "adaptação da OMS às mudanças do mundo", apresentando 47 recomendações à Organização, o que coincide com a emergência da expressão "reforma da OMS” (OMS, 1995). Durante a reunião da 46 a AMS, em 1993, período no qual começava o segundo mandato do diretor-geral Nakajima, foi adotada uma resolução sobre reforma orçamentária (OMS, 1997).

Entre 1993 e 1996, todas as AMSs discutiram mudanças e adaptações da OMS, abordando temas como melhorias de 62 gestão da Organização e dos escritórios regionais, aumento da eficácia dos programas da OMS e otimização da ação da instituição junto aos Estados-membros. O mesmo ocorre com o CE, que também analisa mudanças e uma reforma para OMS (OMS, 1997), o que inclui a discussão de métodos de análise de programas e prioridades conforme orçamento, técnica e recursos disponíveis (OMS, 1995).

Merece destaque a $48^{\mathrm{a}} \mathrm{AMS}$, de 1995, que debateu uma reforma constitucional (OMS, 1997). Embora a Constituição da OMS já tivesse sofrido pequenas emendas, aquela AMS pediu ao CE a revisão geral de um texto que não tinha mudanças substantivas desde 1946. Em 1996, um grupo especial foi estabelecido e, após seis reuniões entre 1996 e 1997, sugeriu algumas mudanças, entre elas o endurecimento de sanções relativas ao não pagamento de obrigações financeiras (Burci e Vignes, 2004). Nenhuma das propostas do grupo foi aceita e o texto da Constituição ainda é basicamente o mesmo de 1946 (Burci e Vignes, 2004). As 
AMSs de 1998 e de 1999 discutiram emendas pontuais à Constituição (OMS, 1998, 1999).

Em 1997, a OMS lançou o documento "Mudanças e Reforma na OMS” (OMS, 1997). Nele, a instituição indica a necessidade de mudanças em razão dos efeitos que o fim da Guerra Fria, a economia de mercado, as reformas democráticas e as crises da dívida tiveram sobre a saúde (OMS, 1997, p. 1), além de justificar a importância do mencionado projeto Saúde para Todos. Segundo o documento, em 1994 a OMS reestruturou seus programas com ênfase no custo/ benefício, transformando 59 programas específicos em apenas 19; as mudanças na forma de lidar com o orçamento decorreriam do aumento das contribuições voluntárias dos Estados, que demandou "novas técnicas de gestão" (OMS, 1997, p. 18). As ações previstas pela OMS naquele período não estipulam prazo para implementação, exceto as relativas ao Saúde para Todos, que devem ser realizadas em menos de uma década (OMS, 1995, 1997). Contudo, a questão da reforma tomou outros rumos com o fim da administração de Nakajima em 1998.

A OMS passa a ser dirigida por Gro Harlem Brundtland, que cria, em 2000, a Comissão de Macroeconomia e Saúde (CMS), relacionando saúde com desenvolvimento econômico e dando importância ao trabalho conjunto com a OMS das agências de Bretton Woods (OMS, 2001). A nova diretora-geral também buscou fortalecer as finanças da OMS por meio de programas inspirados no modelo de parcerias público-privadas (PPPs), aumentando a possibilidade de contribuição voluntária de entidades privadas (Beigbeder, 2010). Embora tenham amenizado os problemas de governança financeira na OMS, essas parcerias aumentaram a influência do setor privado nas políticas de saúde (Birn, 2009), transformando as fundações e inclusive a indústria farmacêutica em parceiros da OMS em programas específicos (Beigbeder, 2010). O redirecionamento de funções e programas antes 
na arena pública, governamental e interestatal para organizações privadas teve consequências significativas em termos de definição de prioridades, propriedades, controle e accountability, reduzindo claramente a importância do sistema onusiano (Kickbusch, 2005, p. 970).

Com as mudanças da gestão Brundtland, os termos "reforma da OMS" e "mudança da OMS" praticamente desaparecem da pauta das AMSs. Contudo, modificações na Organização tiveram curso e estiveram sempre em pauta. Este enunciado contrasta com a afirmação que figura nos documentos atuais da OMS, de que a reforma teve início em 2010 (OMS, 2012e). Assim, pareceu-nos necessária a verificação nos documentos preparatórios das AMSs, de 1998 a 2014, da presença de temas relacionados aos três atuais eixos da reforma. Numa sistematização dos documentos oficiais, tais eixos seriam:

64 1. "Eixo programático - melhores resultados sanitários, correspondendo à OMS uma ação que responda às expectativas de seus Estados-membros e de seus parceiros, conforme as prioridades sanitárias fixadas de comum acordo" (Ventura, 2013a, p. 122), fazendo eco a algumas ideias do início da década de 1990, no sentido de melhorar a eficácia dos programas da Organização e do custo/ benefício das ações;

2. "Eixo de governança - maior coerência da ação sanitária no mundo, reservando à OMS o papel dirigente que permita a numerosos atores contribuir de modo ativo e eficaz para a saúde de todos os povos" (Ventura, 2013a, p. 122), o que inclui o já antigo debate sobre a gestão de parcerias com outras OIs, ONGs e entidades privadas comerciais; e

3. "Eixo de gestão - uma organização que vise à excelência, que seja eficaz, eficiente, reativa, objetiva, transparente e responsável" (Ventura, 2013a, p. 122), referente à governança interna da OMS. 
Para implementar o Eixo ${ }^{\circ} 1$, a OMS desenvolveu cinco critérios: análise da situação atual da saúde, necessidades dos países, instrumentos internacionais já acordados, custo/ benefício e evidência científica das intervenções existentes, e vantagem comparativa da OMS (2012b, p. 4). Trata-se do eixo de análise mais complexo; eis que a OMS aponta, desde a administração Nakajima, a necessidade de melhorar a relação custo/benefício de suas ações, além da eficácia de suas ações locais mediante o aperfeiçoamento de seu diálogo com os Estados-membros.

A Tabela 1 arrola os documentos das AMSs que nos pareceram corresponder aos três eixos atuais de reforma. Foram grifadas as quatro assembleias ocorridas após a afirmação explícita de que uma reforma estava em curso.

Nota-se que, de 1998 a 2010, a AMS continuou debatendo a importância de fortalecer programas mais antigos (como a erradicação da poliomielite e da varíola) e deu ênfase a outros temas, como o fortalecimento dos sistemas de saúde dos países, redução do consumo de tabaco, e prevenção e controle de doenças não transmissíveis. Incentivou a participação de ONGs, sempre destacando a importância de seu papel, de sua liderança e de sua parceria. Por fim, debateu constantemente suas formas de financiamento e a otimização dos recursos disponíveis, além de temas como recursos humanos ou igualdade de gênero em cargos da instituição, sem deixar de abordar a necessidade de ajustes no funcionamento de seus órgãos decisórios. Conclui-se que, sob o slogan de uma reforma ou não, desde os anos 1990 a OMS promove mudanças e adaptações para melhorar sua governança.

Porém, se percebe um hiato entre os projetos de reforma da Organização: existem debates entre 1992 e 1997, e, após esses anos, um longo período no qual a OMS faz adaptações menores ou mudanças pontuais, mas não menos importantes, a exemplo da emenda à Constituição, que 


\section{Tabela 1}

Documentos da Assembleia Mundial da Saúde condizentes com os eixos da reforma 2010-2014*

\begin{tabular}{|c|c|c|c|}
\hline \multirow{2}{*}{ AMS } & \multicolumn{3}{|c|}{ Temas } \\
\hline & Programas e prioridades & Governança & Gestão \\
\hline $51^{a}(1998)$ & A51/5 & WHO/HPR/HEP/98.10 & WHA51.23 \\
\hline $52^{\mathrm{a}}(1999)$ & A52/10 & WHA52.18 & A52/24 \\
\hline $53^{a}(2000)$ & A53/26 Add.1 & WHA53.12 & A53/22 \\
\hline $54^{a}(2001)$ & WHA54.14 & WHA54.14 & WHA54.22 \\
\hline $55^{a}(2002)$ & WHA55.19 & A55/8 & A55/36 \\
\hline $56^{a}(2003)$ & A56/16 & A56/46 & WHA56.34 \\
\hline $57^{a}(2004)$ & WHA57.19 & WHA57.14 & WHA57.8 \\
\hline $58^{a}(2005)$ & WHA58.28 & WHA58.15 & WHA58.20 \\
\hline $59^{a}(2006)$ & A59/19 & WHA59.16 & A59/33 \\
\hline $60^{\mathrm{a}}(2007)$ & WHA60.23 & WHA60.15 & WHA60.9 \\
\hline $61^{\mathrm{a}}(2008)$ & $\begin{array}{c}\text { Debates sobre projetos e } \\
\text { programas }\end{array}$ & $\mathrm{A} 61 / 32$ & WHA61.12 \\
\hline $62^{a}(2009)$ & Ações especialmente sobre gripe & $A 62 / 39$ & WHA62.6 \\
\hline $63^{a}(2010)$ & $\begin{array}{c}\text { Debates sobre projetos e } \\
\text { programas }\end{array}$ & WHA63.10 & $\mathrm{A} 63 / 30$ \\
\hline $64^{a}(2011)$ & \multicolumn{3}{|c|}{3 documentos sobre a reforma, 1 intitulado "Reforma da OMS" } \\
\hline $65^{\mathrm{a}}(2012)$ & \multicolumn{3}{|c|}{12 documentos sobre a reforma, 7 intitulados "Reforma da OMS" } \\
\hline $66^{\mathrm{a}}(2013)$ & \multicolumn{3}{|c|}{7 documentos relacionados à reforma, 3 intitulados "Reforma da OMS" } \\
\hline $67^{a}(2014)$ & \multicolumn{3}{|c|}{2 documentos intitulados "Reforma da OMS" } \\
\hline
\end{tabular}

* Tabela não exaustiva. Numerosos documentos não incluídos demonstrariam também o esforço da OMS em cumprir os objetivos convertidos em três eixos da reforma a partir de 2010. A referência apenas estatística nos anos de 2008 e 2010 se deve ao grande número de documentos encontrados.

Fonte: Elaboração das autoras, com base em OMS (2014d). 
aumentou o número de membros do Conselho Executivo, em 2001.

Esse hiato pode ser entendido como uma resposta direta às crises da Organização, primeiro diante do avanço do neoliberalismo e depois com o advento da pandemia de gripe A (H1N1). O primeiro ciclo de reforma seria uma resposta da organização aos países em via de desenvolvimento e aos problemas da gestão de Nakajima. O segundo seria uma resposta tanto à crise econômica mundial deflagrada em 2008, que restringiu o financiamento da Organização, como à crise da pandemia de gripe.

O novo ciclo de reforma teve início, em 2010, com uma consulta aos Estados-membros sobre o financiamento da Organização. Em janeiro de 2011, Margaret Chan encaminhou os debates que culminaram no programa de reforma, cujos objetivos seriam reforçar o papel de liderança na governança da saúde global, fortalecer sua articulação com outros atores e atender às expectativas dos Estados-membros (OMS, 2011c). Embora coincida com o grande desgaste da OMS durante e após a crise sanitária de 2009-2010, no discurso oficial a reforma se justifica por outras razões, sobretudo operacionais e financeiras.

Entre 2011 e janeiro de 2013, cerca de mil postos de trabalho foram suprimidos, o que foi apresentado por Margaret Chan como parte da reforma que dependia apenas da DG, e que, portanto, poderia ser executada de imediato (OMS, 2013c, p. 5). Embora os dados sobre pessoal sejam opacos, estimamos que essa cifra represente a dispensa de cerca de uma a cada oito pessoas contratadas pela OMS - média que pode ser maior ou menor, a depender do escritório ou programa em questão.

Por fim, gostaríamos de mencionar a participação social na OMS, que será tema de um artigo específico. A Constituição da OMS é pioneira em sua época, ao mencionar o papel da opinião pública e da cooperação ativa da cidadania, e 
também ao prever, em diversos de seus dispositivos, a participação de ONGs nas instâncias da Organização (Ventura, 2013a, p.76). Isso não a poupou de críticas da sociedade civil, que, nos últimos anos, passou a exigir maior participação e a enfatizar o excesso de estado-centrismo da OMS (McInnes e Lee, 2012). No âmbito do atual ciclo de reforma da OMS, um "quadro de colaboração com os atores não estatais" foi proposto pelo Secretariado da OMS (2014e). Ele compreende uma profunda modificação do sistema atual de participação social da Organização, propondo quatro diferentes políticas, a depender do ator em questão ONGs, entidades do setor privado, fundações filantrópicas e estabelecimentos universitários. Essa proposta ainda se encontra em discussão no seio da OMS e merece ser atentamente acompanhada.

\section{A posição do Brasil e a concertação no âmbito da Unasul}

"A OMS é dominada basicamente por três ou quatro. Eles são um grupo que vota, mas também comanda, com outros países, o lado mais retrógrado da OMS"; assim, "hoje, no Brasil, fazemos uma crítica profunda à OMS e pedimos a sua reforma. [...] Não queremos que seja, e não pode ser, uma reforma cosmética" (Buss, s.d.). Essa opinião de um notável sanitarista e negociador brasileiro dá o tom da perspectiva crítica nacional. Isso não significa desinteresse pela Organização. Ao contrário, o Brasil tem se engajado de modo crescente em relação à OMS, tornando-se, em 2013, o décimo maior contribuinte do Orçamento da instituição e elegendo-se membro do CE no período de 2013 a 2016 (Ventura, 2013b, p. 109).

Diplomatas brasileiros criticaram o açodamento com que foi conduzido, inicialmente, o tema da reforma. Tentativas de incluir nos documentos o adjetivo "gradual" teriam sido rechaçadas por influência dos grandes doadores, maiores interessados na aceleração do processo de reforma 
por já terem uma "posição articulada”; criticou-se, ainda, a supressão da expressão "saúde e desenvolvimento" dos documentos da reforma (Unasul/ISAGS, 2012, p. 4).

Por outro lado, desde a criação do Conselho Sul-Americano de Saúde no âmbito da Unasul, teve início a concertação das posições dos Estados-membros da organização regional no seio da OMS, com reuniões paralelas à AMS, a fim de adotar posições comuns, inclusive no Conselho Executivo da organização (Ventura, 2013b, p. 109).

Durante a $65^{\mathrm{a}}$ AMS, os Estados-membros da Unasul defenderam "uma reforma da OMS mais ampla do que a revisão das formas de financiamento, como inicialmente previsto" (Unasul/ISAGS, 2012, p. 1). Eles criticaram igualmente as prioridades de atuação da OMS propostas pela DG na mesma ocasião, que seriam: (1) Doenças transmissíveis; (2) Doenças não transmissíveis; (3) Promoção da saúde ao longo da vida; (4) Sistemas de saúde; e 5) Prevenção, vigilância e resposta (OMS, 2012b). À época Coordenador

Nacional do Brasil na Unasul Saúde, Paulo Buss sublinhou a ausência da produção social da saúde entre tais categorias, ora focadas na ruptura da normalidade biológica; sua sugestão é de que as atuais categorias 1, 2 e 5 sejam mescladas sob o nome Vigilância em saúde, e que uma sexta categoria seja acrescentada para aportar os temas saúde, desenvolvimento e determinantes sociais da saúde (Unasul/ISAGS, 2012, p. 3).

Segundo David Held (2007, p. 434), o desenvolvimento do multilateralismo e do direito internacional criou "enclaves cosmopolitas" em todo o mundo; novos espaços deliberativos internacionais vêm surgindo para abrigar coalizões de atores comprometidos com os direitos humanos, de defensores de uma ordem econômica internacional mais justa 
ou mais estável e de movimentos sociais transnacionais de resistência aos efeitos negativos da globalização econômica.

Apesar das diferenças entre esses grupos, tais enclaves têm o intuito de permitir a identificação de interesses comuns, como o de "criar novas instituições" capazes de "prover bens públicos globais, regular mercados mundiais, aprofundar responsabilidades, proteger o meio ambiente e enfrentar urgentemente as injustiças sociais que matam milhares de homens, mulheres e crianças a cada dia" (Held, 2007, p. 435).

Questionar a possibilidade de transformação da OMS em um enclave cosmopolítico implicaria aferir as suas possibilidades de atuação no que se refere a cada uma dessas tarefas, o que ultrapassa largamente o escopo deste artigo. Lançar a questão, porém, permite perceber a pouca ambição da reforma da OMS.

Salta aos olhos que a questão do financiamento só pode70 ria ser solucionada com o aumento da contribuição fixa dos Estados-membros da Organização. Todavia, num momento de recessão econômica e sob a pressão dos seus maiores financiadores, que se encontram no setor privado, a DG propugna um debate sobre soluções técnicas e gerenciais, e não uma abordagem política (Ventura, 2013a). Trata-se, essencialmente, de reduzir o pessoal da Organização, eleger melhor as suas prioridades e azeitar as suas dinâmicas institucionais (OMS, 2013a).

É notável a ausência, nos documentos estudados, de propostas de criação de mecanismos de transparência e prestação de contas capazes de restabelecer a credibilidade da Organização, especialmente no que atine à identificação de quais são os interesses e motivações dos financiadores a cada programa proposto ou implementado (Maruthappu e Williams, 2012).

O percurso feito neste artigo revela, portanto, um fenômeno mais geral, que acomete a saúde global em seu con- 
junto, qual seja, a apropriação de imperativos como o de "salvar vidas" ou o de "aumentar o acesso à saúde" como mote para amálgamas entre atores estatais, empresariais e movimentos sociais, sem que uma crítica a essas agendas comuns consiga ser formulada (Biehl e Petryna, 2013, p. 7), especialmente quanto aos seus limites; aos interesses, opacos ou não, dos atores envolvidos; e aos efeitos menos visíveis sobre a governança, nacional e internacional, a médio e longo prazo, dos programas implementados.

Apesar de todas as críticas que arrolamos, acreditamos que "não há substituto para a OMS" (Sridhar e Gostin, 2011, p. 1586), no sentido de que não existe, no cenário internacional, outra entidade pública capaz de liderar as iniciativas de saúde que correspondam aos interesses da maioria das populações. Um estudo recente revela que $90 \%$ dos atores que participam da ação sanitária mundial acreditam que a OMS ainda é a organização que mais influencia as políticas de saúde (Kastler, 2013). Logo, é inaceitável que ela se converta em um simples serviço técnico destinado a paliar as consequências nefastas do nosso modo de vida atual (Danzon e Charpak, 2012). Este é apenas um entre os muitos riscos que emergem do tecnocrático processo de reforma da OMS. Para uma crise exuberante, uma reforma acanhada.

\section{Deisy Ventura}

é professora de Direito Internacional e livre-docente do Instituto de Relações Internacionais da USP; e bolsista de Produtividade em Pesquisa do CNPq - nível 2.

\section{Fernanda Aguilar Perez}

é mestre em Saúde Pública pela USP e doutoranda (bolsista da Capes) do Programa de Pós-Graduação em Relações Internacionais da mesma universidade. 


\section{BIBLIOGRAFIA}

ABBASI, K. 1999. "The World Bank and world health: changing sides".

BMJ - British Medical Journal, n. 318, pp. 865-69.

APCE - Assembleia Parlamentar do Conselho da Europa. 2010a.

Recomendação 1929, de 24 de junho. Estrasburgo: APCE. . 2010b. Resolução 1749, de 24 de junho. Estrasburgo: APCE.

BANCO MUNDIAL. 2013. Relatório anual 2013. Washington: Banco Mundial.

BEIGBEDER, Y. 2010. "Le partenariats de l'Organisation Mondiale de la Santé”. Revue Études Internacionales, v. XLI, n. 2, pp. 233-51.

BERLINGUER, G. 1999. "Globalização e saúde global”. Estudos Avançados, v. 13, n. 35, pp. 21-38.

BIEHL, J.; PETRYNA, A. 2013. "Critical global health". In: BIEHL, J.; PETRYNA, A. (orgs.). When people come first-critical studies in global health. Princeton: Princeton University Press. pp. 1-22.

BIRN, A. 2009. "The stages of international (global) health: histories of success or successes of history?”. Global Public Health, v. 4, n. 1, pp. 50-68.

BMJ - British Medical Journal. 1973. Editorial: "Dr. M.G. Candau and WHO”. BMJ-British Medical Journal, v. 2, n. 5.864, pp. 43334. Disponível em: <http://www.ncbi.nlm.nih.gov/pmc/articles/ PMC1589468/>. Acesso em: 31 maio 2011.

BROWN, T; CUETO. M; FEE, E. 2006. "The World Health Organization and the transition from international to global public health". American Journal of Public Health, v. 96, n. 1, pp. 62-72.

BURCI, G. 2012. "Navigating the new field of international health law". Áudio. Conferência ministrada em 22 fev. 2012. Disponível em: <http://75.127.192.36/Health_Law_WHO_Feb_22.asx >. Acesso em: 24 mar. 2012.

BURCI, G.; VIGNES. C. 2004. World Health Organization. Haia: Kluwer Law International.

BUSS, P. s.d. Entrevista concedida a Isabela Schincariol. Portal ENSP -

Noticia. Disponível em: <www.ensp.fiocruz.br>. Acesso em: 14 set. 2012.

BUSS et al. 2012. "Governança em saúde e ambiente para o desenvolvimento sustentável”. Ciência Ẽ Saúde Coletiva, Rio de Janeiro, v. 17, n. 6, pp. 1484-1491.

BUSSARD, S. 2012. "L'OMS crève un abcès en publiant le nom de ses experts”. Le Temps, 12 ago.

CHARPAK, Y. 2012. "Focus OMS - Ce qui la France pourrait faire". Les Tribunes de la Santé, n. 35, pp. 13-14. 
2013. “OMS - Ces débats qui n'arrivent pas à nos oreilles...”. Les Tribunes de la Santé, n. 38, pp. 13-14.

CHOREV, N. 2012. The World Health Organization between North and South. Ithaca, NY: Cornell University Press.

CHOW, J.C. 2010. "Is the WHO Becoming Irrelevant?". Foreign Policy, 8 Dec. Disponível em <http://www.foreignpolicy.com/articles/2010/12/08/ is_the_who_becoming_irrelevant>. Acesso em: 28 fev. 2014.

COHEN, D.; CARTER, P. 2010. "Conflicts of interest - WHO and the pandemic flu 'conspiracies'”. BMJ - British Medical Journal, n. 340. Disponível em: <http://www.bmj.com/content/340/bmj.c2912.full>. Acesso em: 18 fev. 2012.

CUETO, M. 2013. “A return to the Magic Bullet?”. In: BIEHL, J.; PETRYNA, A. (orgs.). When people come first-critical studies in global health. Princeton: Princeton University Press. pp. 30-53.

DANZON, M.; CHARPAK, Y. 2012. "L'Oms peut jouer un rôle dans cette période de grave crise économique et sociale”. Le Monde, 18 jan.

DEVEAUD, B.; LEMENNICIER, B. 1997. L'OMS: bateau ivre de la santé publique - Les dérives et les échecs de l'agence des Nations Unies. Paris: L'Harmattan.

ENSERINK, M. 2009. "In Holland, the public face of flu takes a hit". Science, v. 326, n. 5951, pp. 350-51. Disponível em: <10.1126/ science.326_350b>. Acesso em: 15 jun. 2014.

FIDLER, D. 2001. "The globalization of public health: the first 100 years of international health diplomacy". Bulletin of the WHO, v. 79, n. 9, pp. 842-49.

FINEBERG, H. 2011. "Prefácio". In: OMS. A64/10 - Report of the Review Committee on the Functioning of the International Health Regulations (2005) in relation to pandemic (H1N1) 2009. Genebra: OMS. pp. 6-7.

FRANÇA. Senado. 2010a. Proposition de Résolution [ $n^{\circ} 226$ ] visant à créer une commission d'enquête sur le rôle des firmes pharmaceutiques dans la gestion par le gouvernement de la grippe A (H1N1). Paris: Senado.

.2010b. Rapport de la commission d'enquête sur le role des firmes pharmaceutiques dans la gestion par le gouvernement de la grippe A (H1N1). Paris: Senado. Tomos I e II.

GODLEE, F. 1994. "The World Health Organisation: WHO in crisis". BMJ - British Medical Journal, n. 309, pp. 1424-29.

. 2010. "Conflicts of interest and pandemic flu - WHO must act now to restore its credibility, and Europe should legislate". BMJ-British Medical Journal, n. 340. Disponível em: <www.bmj.com/content/340/ bmj.c2947.full>. Acesso em: 18 fev. 2012. 
GOSTIN, L. 2007. "Meeting the survival needs of the world's least healthy people - a proposed model for global health governance". JAMA - The Journal of the American Medical Association, v. 298, n. 2, pp. 225-28.

HELD, D. 2007. Modelos de democracia. 3. ed. Madrid: Alianza.

KAPLAN, 1983. "Dr. M. G. Candau, a personal appreciation”. World Health Forum, v. 4, pp. 2-3.

KASTLER, F. 2013. "Focus OMS - Des résolutions et une réforme cruciale en cours". Les Tribunes de la Santé, n. 39, pp. 13-14.

KEROUEDAN, D. 2013. Géopolitique de la santé mondiale. Paris: Collège de France/Fayard. [Leçons inaugurales du Collège de France $n^{\circ} 34$ ].

KICKBUSCH, I. 2005. "Action on global health: addressing global health governance challenges”. Public Health, v. 119, n. 11, pp. 969-73.

KICKBUSCH, I.; IVANOVA, M. 2013. "The history and evolution of global health diplomacy". In: KICKBUSCH et al. (eds.). Global health diplomacy: concepts, issues, actors, instruments, fora and cases. New York: Springer.

LAUDE, A.; MATHIEU, B.; TABUTEAU, D. 2007. Droit de la santé. Paris: PUF.

LEGGE, D. 2012. "Future of WHO hangs in the balance". BMJ-British Medical Journal, n. 345. Disponível em: <http://www.bmj.com/ content/345/bmj.e6877>. Acesso em: 25 abr. 2013.

74 LIMA, N. 2002. "O Brasil e a OPAS: uma história em três dimensões". In: FINKELMAN, J. (org.). Caminhos da saúde pública no Brasil. Rio de Janeiro: Ed. Fiocruz.

LUCCHESE, G. 2003 “A internacionalização da regulamentação sanitária”. Ciência Ẽ Saúde Coletiva, v. 8, n. 2, pp. 537-55.

MARUTHAPPU, M.; WILLIAMS, C. 2012. "Reversing the WHO crisis: transparent priority matching of global needs with donor objectives”. BMJ - British Medical Journal, n. 345. Disponível em: <http://www.bmj. com/content/345/bmj.e7815>. Acesso em: 22 dez. 2013.

MBENGUE, M. M. 2006. "Technique de l'opting out: acceptation par les États des normes techniques internationales”. In: BROSSET, E.; TRUILHÉ-MARENGO, E. Les enjeux de la normalisation technique internationale - entre environnement, santé et commerce internationale. Paris: Ceric/La Documentation Française.

McINNES, C; LEE, K. 2012. Global health and international relations. Malden, MA: Polity Press.

MUNIZ, E. S. 2011. "Memórias da erradicação da varíola". Ciência Ẽ Saúde Coletiva, v. 16, n. 2, pp. 699-701.

NUNES, J. 2014. Security, emancipation and the politics of health. London/ New York: Routledge. 
NURUZZAMAN, M. 2007. "The World Bank, health policy reforms and the poor”. Journal of Contemporary Asia, v. 37, n. 1, pp. 57-72.

OMS - Organização Mundial da Saúde.1946. Constituição. Disponível em: <http://www.who.int/governance/eb/who_constitution_en>. Acesso em: 13 jul. 2014.

1958. Les dix premières années de L’Organisation Mondiale de la Santé,

Genebra: OMS.

1995. PPE/95.4 22. Adaptation de l'OMS aux changements mondiaux.

Genebra: OMS.

1997. Reforms 97.1 Changes and reform at WHO. Genebra: OMS.

1998. WHA 51.23 Amendments to articles 24 and 25 of the Constitution.

Genebra: OMS.

1999. A52/24. Amendments to the Constitution: Report by the

secretariat. Genebra: OMS.

2001. Comissão de Macroeconomia e Saúde. Macroeconomia e saúde:

investindo em saúde para o desenvolvimento econômico. Genebra: OMS.

2005. Plan mondial de préparation à une pandémie de grippe-Le rôle

de l'OMS et les recommandations relatives aux mesures à prendre à

l'échelon national avant e pendant une pandémie. Genebra: OMS.

2006. GPW/2006-2015 - Contribuir a la salud. Undécimo Programa

General de Trabajo, 2006-2015. Un programa de acción sanitaria

mundial. Genebra: OMS.

2008. Règlement sanitaire international-États parties au RSI.

Genebra: OMS.

. 2009. "WHO use of advisory bodies in responding to the influenza pandemic". Pandemic (H1N1) 2009 briefing note n. 19, Genebra: OMS, 3 Dec. Disponível em: <http://www.who.int/csr/disease/swineflu/ notes/briefing_20091203/en/index.html>. Acesso em: 14 fev. 2012. . 2010a. "H1N1 in post-pandemic period. Director-General's statement". Genebra: OMS, 10 Ago. Disponível em: <http://www.who. int/mediacentre/news/statements/2010/h1n1_vpc_20100810/en/>. Acesso em: 17 fev. 2012.

. 2010b. Statement of the World Health Organization on allegations of conflict of interest and "fake" pandemic. Genebra: OMS, 22 Jan. Disponível em: <http://www.who.int/mediacentre/news/statements/2010/h1n1_ pandemic_20100122/en/index.html>. Acesso em: 14 fev. 2012.

. 2010c. "WHO Director-General's letter to BMJ editors", Statement. Genebra, 8 June. Disponível em: <http:/ /www.who.int/mediacentre/ news/statements/2010/letter_bmj_20100608/en/index.html >. Acesso em: 17 fev. 2012. 
2011a. A64/10 - Report of the review committee on the functioning of the international health regulations (2005) in relation to pandemic (H1N1) 2009. Genebra: OMS.

2011b. EBSS/2/INF.DOC./2 Financing of the World Health

Organization. Genebra: OMS.

2011c. EB128/INF.DOC./3 The future of financing for WHO - Summary of the director-general's concluding remarks. Genebra: OMS.

. 2012a. A65/29 Add.1 - Annex - Voluntary contributions by fund and by donor for the financial period 2010-2011. Genebra: OMS.

. 2012b. A65/40. WHO Reform. Report by the director general.

Genebra, OMS.

. 2012c. EB130/INF.DOC./2 Déclaration du représentant des Associations

du Personnel de l'OMS. Documento de informação. Genebra, 19 jan.

. 2012d. EB132/15 - Application du RSI (2005) - Rapport du directeur

général. Genebra: OMS.

2012e. Report on WHO reform development phase 2011-12. Genebra:

OMS.

. 2013a. EB132/INF./3 - Implementation of WHO reform, 2012 - High-

level implementation plan. Genebra: OMS.

2013b. "Schistosomiasis: number of people treated in 2011". Weekly

Epidemiological Record, n. 8, 22 Feb., pp. 80-88.

. 2013c. EB132/2 - Report by the director-general to the executive board at its 132nd session. Genebra: OMS.

. 2014a. A67/4 - WHO reform. Progress report on reform

implementation. Genebra: OMS.

. 2014b. A67/42 - Budget programme 2012-2013: appréciation de

l'exécution. Genebra: OMS.

. 2014c. World Health Organization [site oficial]. Disponível em:

<http://www.who.int/en/>. Acesso em: 13 jul. 2014.

2014d. World Health Assemblies. Institutional repository for

information sharing. Disponível em: <http://apps.who.int/iris/>. Acesso em: 31 maio 2014.

. 2014e. A67/6 - Framework of engagement with non-State actors.

Genebra: OMS.

2014f. A67/DIV/6 - Address by Melinda Gates, Bill Ẽ Melinda Gates

Foundation, to the sixty-seventh World Health Assembly. Genebra: OMS.

OMS; UNICEF [Fundo das Nações Unidas para a Infância]. 2014. Progress on drinking water and sanitation: 2014 update. Genebra: OMS/Unicef.

OMS; UNICEF; Banco Mundial; United Nations Population Division. 2014. Trends in maternal mortality: 1990 to 2013. Genebra: OMS. 
RUGER, J. P. 2005. "The changing role of the World Bank in global health". American Journal of Public Health, v. 95, n. 1, pp. 60-70.

SIMONSEN, L. et al. 2013. "Global mortality estimates for the 2009 influenza pandemic from the GLaMOR Project: a modeling study". PLoS Med, v. 10, n. 11. Disponível em: <doi:10.1371/journal. pmed.1001558>. Acesso em: 15 jun. 2014.

SRIDHAR, D.; GOSTIN, L. 2011. "Reforming the World Health Organization". JAMA - The Journal of the American Medical Association, v. 305 , n. 15 , pp. $1585-86$.

TOLLISON, R. D.; WAGNER, R. E. 1993. Who benefits from WHO? Decline of the World Health Organization (research reports). London: Social Affairs Unit.

UNASUL/ISAGS - União Sul-Americana de Nações/Instituto SulAmericano de Governo em Saúde. 2012. Informe. 65 ${ }^{a}$ AMS discutiu reforma da OMS com destacada atuação da UNASUL. Rio de Janeiro: ISAGS. Disponível em: <http:/ /isags-unasul.org>. Acesso em: 25 abr. 2014.

VENTURA, D. 2013a. Direito e saúde global. São Paulo: Expressão Popular/ Dobra Editorial. . 2013b. "Saúde pública e política externa brasileira". Sur-Revista Internacional de Direitos Humanos, v. 10, n. 19, pp. 109-17.

ZYLBERMAN, P. 2012. "Crises sanitaires, crises politiques”. Les Tribunes de la Santé, n. 34, pp. 35-50. 


\section{CRISE E REFORMA DA ORGANIZAÇÃO MUNDIAL DA SAÚDE DEISY VENTURA}

\section{FERNANDA AGUILAR PEREZ}

Resumo: $\mathrm{O}$ artigo mostra que crise e reforma são temas recorrentes nas últimas três décadas de funcionamento da Organização Mundial da Saúde (OMS). Após breve apresentação da Organização, os principais elementos de sua crise são identificados, graças à revisão da literatura e à pesquisa documental. A seguir, o artigo arrola sinteticamente os resultados de pesquisa empírica sobre as temas relacionados à reforma, incluídos nas pautas da Assembleia Mundial da Saúde, de 1998 a 2014. Adiciona-se uma breve alusão às posições do Brasil e da União Sul-Americana de Nações (Unasul) sobre a crise e a reforma em tela. Na conclusão, questiona-se se tal reforma poderia tornar a OMS uma espécie de "enclave cosmopolítico" na complexa configuração da saúde global.

Palavras-chave: Organizações Internacionais; Organização Mundial da Saúde; Saúde Global.

\section{CRISIS AND REFORM OF WORLD HEALTH ORGANIZATION}

Abstract: This article explains that crisis and reform are two usual topics in the last three decades of the World Health Organization work. After briefly introducing the organization, the crisis main characteristics are identified by literature review and documentary analysis. Subsequently, results from empirical research on the reform agenda in the World Health Assembly sessions from 1998 to 2014 are listed. A short mention to Brazil's and Union of South American Nations' positions regarding the organization reform is also introduced. On the conclusion, a deliberation upon the possibility of WHO becoming, due to the ongoing reform, a "cosmopolitan enclave" in the complex global health framework is proposed.

Keywords: International Organizations; World Health Organization; Global Health. 